with the position of the furrows. The closer they approach to the contours the longer the furrows may be and the greater will be their storage capacity.

As yet the basin cultivator has not been adapted to grains such as wheat, since there is no seeding device capable of planting the seeds at the different depths that would be required on a field prepared by a basin cultivator. The objections advanced, however, are not serious enough to prevent the use of the basin lister for other crops or to discourage further experimentation.

\title{
Science and Industry at the Empire Exhibition, Glasgow
}

$\mathrm{T}$ HE exhibits in three of the large exhibition halls in the United Kingdom Government Pavilion at the Empire Exhibition, Glasgow, opened by H.M. the King on May 3, have been arranged by the Department of Scientific and Industrial Research in close collaboration with industry. The aim of the halls is to show the relationship now existing between science and industry, and the part which science has played in the development of British industry. The theme is illustrated by the three great national industries of coal, iron and steel, and shipbuilding-one of the exhibition halls being devoted to each of these industries. The subjects of the halls were chosen on the advice of a committee which included some of the greatest industrial leaders in the country.

In telling the story of the place which science is taking in modern industry, practically every device of modern display has been employed to make the exhibits attractive and interesting. In this work the Department has had the help of a distinguished display expert.

Everywhere the visitor finds colour and movement. Complicated processes are simplified and traced out for him by moving lines of light. Where possible, working models are used, and elsewhere essential points are explained by short cinema films introduced into the various sections of the exhibit. The meaning underlying the halls is made plain by large murals. Many of the exhibits are demonstrated by members of the staff of the Royal Technical College, Glasgow. A novel feature of the halls is, that in the sections where a demonstrator is not provided, the various exhibits are explained in conversational tones by loudspeakers radiating the story of the section and directing attention to the various points. For this purpose a new system of sound recording employing a narrow strip of film is being used.

The first of the three industrial research halls is devoted to coal. The most prominent single exhibit in the hall is a large working model of a coal mine more than 200 square feet in area and fifteen feet in height. This has been provided for the Pavilion by the Mining Association of Great
Britain, and is probably the finest model of its kind in the world. Both underground and surface workings are illustrated in detail. The latest methods of winning coal are demonstrated and near by are exhibits illustrating the work of the Safety-in-Mines Research Board and the Miners' Welfare Committee. There are also sections dealing with the preparation of coal for the market, which show that coal as supplied to the consumer to-day has ceased to be a crude raw material and has become more and more a semi-manufactured article. Entering the hall, there is a section dealing with the origin of coal. Here there is a large representation of what a coal forest looked like some two hundred million years before the appearance of man. A short cinema film shows how the debris of such a forest was converted into coal seams. The immense varieties of British coal are illustrated by a number of pillars cut from various coal seams. In the next section of the hall the work of the National Coal Survey is illustrated, and the way in which the immense amount of knowledge now available concerning the properties of coal is being used for its better utilization. The next section deals with the great advances which have been made in the use of coal for steam generation both in large power stations and in smaller industrial plants. Here, for example, it is shown that the amount of electricity which can be obtained from a ton of coal has increased by more than 60 per cent in the last twelve years and that, in addition, improvements in electric lamps and other appliances enable electricity to be used more economically. An interesting display shows the products of combustion in super-power station practice, in good and bad industrial practice, and in domestic heating. Something of the latest researches in domestic heating which are now being carried out is also illustrated.

The other side of the hall is devoted entirely to an exhibit prepared by the British Gas Federation dealing with the carbonization of coal in gasworks, coke ovens and low-temperature carbonization plants. The whole process of the treatment of coal and also many of the by-products 
produced are shown. The essential parts of the various plants are represented, and the course taken by the coal into these is traced by moving light. Light of a different colour shows the passage of the gas through the various stages and the methods by which impurities are extracted from it and converted into valuable products. In front of these diagrams are scenes showing the industries in which these by-products of coal are used, and below these again are fascinating models showing the finished articles which coal has helped to make. The centre of the hall is taken up by a large section illustrating the modern use of coal as a raw chemical material. Various processes for obtaining oil from coal are illustrated here, and it is shown how the gases produced by passing steam over red-hot coke or coal can be synthesized into motor spirit, industrial alcohol and other products. The use of coal as a raw material in the carbide industry, in the production of active carbon and in the making of electrodes is also illustrated.

In the Iron and Steel Hall the visitor will find a huge model of a blast furnace more than thirty feet in height. The furnace itself is made in glass and reveals the red-hot charge within and the molten iron apparently running into the pig beds. The right-hand side of the hall is devoted to the production of iron and steel from the ore to the finished product. To enable the layman to appreciate some of the research problems involved, an attempt has been made to show something of what goes on inside the steel furnace. This has been done by the use of moving coloured models partly made in glass. They indicate, for example, the importance of the heat resistance of the brick linings of the furnace. Industry spends $\mathfrak{3}, 000,000$ a year in the replacement of these, which represents $5 s$. of the cost of every ton of steel made. Here is obviously a problem of research, in which, by the way, great progress is being made. The importance of controlling the various processes by scientific instruments is brought out and the ways in which science is helping towards improvements in efficiency and reduction of waste in every form.

Two sections of the hall deal with the microscope and X-rays. The use of the microscope to reveal the inner structure of metals is demonstrated, together with the way in which such knowledge is being used to produce stronger but lighter steels, besides steels possessing special properties. In the X-ray section a powerful equipment for $\mathrm{X}$-ray analysis is shown working, and the visitor learns how, by this means, the physicist can deduce the actual arrangement of the atoms from which the crystals seen in the microscope are built up. Both the use of the microscope and the X-ray apparatus is demonstrated by the staff of the Royal Technical College, Glasgow.

Finally, the way in which steel is used for various engineering purposes is illustrated and an attempt is made to show the visitor how an engineer would select a steel for a particular job and the kind of forces the steel would have to withstand. Progress in constructional steels, for example, is illustrated by a series of model bridges of increasing span constructed of cast iron, mild steel and alloy steel. The load on the bridges consists of a model train. The visitor is reminded of the immense savings, amounting to many millions of pounds a year, resulting from the use of improved steels produced by scientific research, and of the way in which these steels are enabling what were once the luxuries of the few to be brought within the reach of millions. Just before the visitor leaves the hall, an interesting small section directs his attention to the increase in value of iron resulting from research and craftsmanship, which shows that iron in the form of iron ore is worth about 34s. a ton, while in the watch-spring, for example, it is worth perhaps $£ 4,000,000$ a ton.

In the Shipbuilding Hall the subject has been treated in three parts-the hull, the engines and navigation. Improvements in the lines of the hull have come about as the result of 'tank' research. There is a working model of the famous Yarrow Tank and the workshops associated with it at the National Physical Laboratory. While such a model brings out the length of the modern tank, it can convey very little idea of the actual type of the model hull used in the work or of the instruments employed. Accordingly a $16 \mathrm{ft}$. wax model of a hull fitted with the necessary recording instruments is also shown. Recent research on the phenomenon of cavitation is illustrated by a propeller-tunnel in which a propeller is shown running under conditions which produce cavitation.

Turning to the marine engine, working models of three of the latest types of turbine, reciprocating engine, and oil engine are shown. In another exhibit the development is traced of the steam engine and its efficiency from the time of Watt to the present day.

The results of research in shipbuilding are summed up in one section of the hall. Here it is shown that the fuel consumption of an ordinary cargo vessel of, say, 9,000 tons steaming at 10 knots, has been reduced by nearly half in the last fifteen years as the result of research. How this remarkable result has been brought about is shown by a representation of a cargo vessel of fifteen years ago, which fades before the eyes of the onlooker to the same type of ship as would be built to-day. 
One of the most popular exhibits in the hall is a very realistic ship's bridge carrying the wheelhouse and chartroom of a cargo liner. Practically all the navigating instruments found on such a vessel, including the gyro-compass, the echo depthsounder and the wireless direction-finder are arranged so far as possible to simulate working conditions. The visitor is able to handle these instruments and to have their principles explained to him by the 'captain', the 'chief officer' or the 'quartermaster'. Elsewhere in the hall the principles underlying some of these instruments are demonstrated in other ways. In this section also there is a fascinating display illustrating a cathode ray direction-finder which gives the bearings of a distant station instantaneously.
Another exhibit which is proving very popular is the wireless office of a British destroyer manned by naval ratings.

The large mural, $1,500 \mathrm{ft}$. square, over the exit of the hall is a striking example of the industrial co-operation which has made the exhibits possible. On this mural are displayed silhouettes of every vessel of more than 100 tons gross launched from British yards last year; they include liners, tanker vessels and smaller craft, besides warships of every description. Some four hundred ships, of capital value $£ 46,000,000$, are represented according to the town in which they were built. Every shipbuilding firm in the country has contributed to this remarkable feature by supplying silhouettes of the ships built in its yards.

\section{Obituary Notices}

\section{Colonel Marcuswell Maxwell}

$\mathrm{C}$ YOLONEL MARCUSWELL MAXWELL, who died suddenly in a Nairobi nursing home on April 21, was one of the most successful photographers of wild life in East Africa, his photographs of lions, elephants, giraffes, rhinoceroses and other big game being some of the best ever taken, while his photographic studies of the eastern gorilla have never been surpassed. He shared with his namesake, Marius Maxwell, the distinction of being not only a photographer but also a photographic artist in that nearly every exposure he made was a picture.

Maxwell's photographs of East African big game have from time to time appeared in the pages of The Times and were published in book form, in two volumes, by The Times in 1930. One of these volumes, entitled "Elephants and Other Big Game Studies", contains eleven magnificent photographs of the African elephant, the majority of which were taken at close quarters. These are followed by photographs of black rhinoceros, waterbuck, hunting dogs, hyaenas, impala, eland, zebra, giraffe, wildebeest and vultures. The other volume, entitled "Big Game Photographs", commences with a series of photographs of the well-known Serengeti lions, among them some of the most amazing close-ups of these large carnivora that have ever been secured. There is also an interesting study of a lion climbing a tree, showing that these animals do occasionally exhibit arboreal habits. In this volume, there are also photographs of a rhinoceros accompanied by tick-birds, giraffes in the open, a wonderful study of buffaloes in cover, two wart-hogs at home and a general view of waterbuck at a water-hole.

It is a sad coincidence that death should have overtaken both Marcuswell and Marius Maxwell, two of our most prominent animals photographers. They were not related, but their names and photographic work being so similar frequently led to confusion between the two. This was accentuated by the fact that, in addition to both photographing wild life in Kenya Colony, they both visited the Birunga range of volcanoes in the eastern Belgian Congo in the hopes of photographing the eastern gorilla. Here Marcuswell was more successful than Marius, the latter encountering abnormally bad climatic con. ditions even for these equatorial forests. Some of Marcuswell Maxwell's photographs of gorillas will never be bettered; he had the good fortune to come up close to an old male gorilla and his family, and without very much interference from the ground vegetation was able to take some excellent pictures.

Zoological science, naturalists and sportsmen have lost a very ardent worker in the death of Marcuswell Maxwell, and he leaves a blank which will be very difficult to fill.

GuY Dollman.

\section{Prof. J. E. Johansson}

Prof. J. E. Johansson, of Stockholm, died on March 31, at seventy-six years of age. Johansson was professor of physiology at the Caroline Institute in Stockholm from 1901 until 1927. His first degree was in physics and mathematics. He then studied physiology with Holmgren in Uppsala, and in 1889 he worked with Ludwig in Leipzig. In 1890 he was awarded his M.D. degree for a thesis on the splanchnic nerves and was appointed reader in Tigerstedt's laboratory at Stockholm. From 1890 until 1908, he carried out his well-known researches on metabolism, particularly in connexion with muscular exercise. From 1908 onwards, however, his spare time was chiefly occupied with various activities on behalf of the Swedish Government. He was chairman also (until 1926) of the Medical Nobel Committee, and the high standard which he maintained gave him an enormous amount of work in studying the claims of persons proposed for the Nobel Prize in physiology and medicine. 